\title{
A PEDAGOGIA DO AFETO EM NIETZSCHE-SPINOZA: CONSI- DERAÇÕES A PARTIR DA LEITURA DE DELEUZE
}

\author{
THE PEDAGOGY OF AFFECTION IN NIETZSCHE-SPINOZA: considerations from \\ Deleuze reading
} LA PEDAGOGÍA DEL AFECTO EN NIETZSCHE-SPINOZA: consideraciones de
lectura Deleuze

\author{
Deniz Alcione Nicolay \\ Professor Doutor da Universidade Federal da Fronteira Sul (UFFS). \\ deniznicolay@uffs.edu.br
}

\begin{abstract}
RESUMO: O presente texto trata do encontro Nietzsche-Spinoza. Tal encontro é promovido, sobretudo, pela filosofia deleuziana. A partir dessa perspectiva filosófica, este texto discute as noções de imanência e afetividade. Volta-se para o livro III da Ética de Spinoza na intenção de operar com a teoria dos afetos nas relações entre conhecimento e vida, corpo e espírito. Por isso, analisa as distinções utilizadas por Nietzsche e Spinoza no que concerne ao uso dos conceitos de Vontade de Potência e conatus. Identifica a alegria como o elo que anima essa relação, quer seja na dimensão intensiva, quer seja na dimensão trágica. O fato é que a filosofia de ambos enobrece o esforço humano em dar forma a natureza, a arte e a cultura. Nesse sentido, em contraponto as pedagogias da essência, apresentamos a possibilidade de pensar uma pedagogia do afeto. Em tal pedagogia o conhecimento é uma aventura infinita, mas não impossível de ser vivida. Trata-se de uma pedagogia da realidade, que visa à superação de barreiras (psíquicas ou institucionais), utilizando a positividade como parâmetro, a grandeza como modelo. Por fim, pregando um estatuto de cientificidade ao afeto, essa pedagogia não isola a vida do processo, mas é a vida mesma nas suas variações de potência.
\end{abstract}

PALAVRAS-CHAVE: Afetividade. Conhecimento. Paixão. Alegria.

ABSTRACT: This paper deals with the meeting Nietzsche-Spinoza. This meeting is organized mainly by Deleuzian philosophy. From this philosophical perspective, this paper discusses the notions of immanence and affectionateness. Back to the book III of Spinoza's Ethics, aiming to operate on the theory of affects in relations between knowledge and life, body and spirit. Therefore, analyzes the distinctions used by Nietzsche and Spinoza about use of the concepts "Desire for Power" and "conatus". Identifies the joy as the link that animates this relationship, whether in the intensive dimension, whether in the tragic dimension. The fact is that the philosophy of both ennobles the human effort in shaping the nature, art and culture. In this sense, contrasting the pedagogies of the essence, we present the possibility of thinking a pedagogy of affection. In such a knowledge, the pedagogy is an endless adventure, but not impossible to be lived. It is a pedagogy of reality, which aims at overcoming barriers (mental or institutional) using the positivity as a parameter, the greatness as a model. Finally, preaching a scientific status to the affection, this pedagogy does not isolate the process of life but is life itself in its power variations.

KEYWORDS: Affectivity. Knowledge. Passion. Joy.

RESUMEN: Este artículo trata de la reunión Nietzsche-Spinoza. Este encuentro está organizado principalmente por la filosofía Deleuziana. Desde el punto de vista filosófico, este documento analiza los conceptos de la imanencia y el afecto. Volver al libro III de la Ética de Spinoza se pretende utilizar en la teoría de los afectos en las relaciones entre el conocimiento y la vida, el cuerpo y el espíritu. Por lo tanto, los análisis de las distinciones utilizadas por Nietzsche y Spinoza en respecto al uso de la voluntad de los conceptos de voluntad de poder y conatus. Identifica la alegría como el vínculo que anima a esta relación, ya sea en la dimensión intensiva, ya sea en la dimensión trágica. El hecho es que la filosofía de ambos ennoblece el esfuerzo humano en la conformación de la naturaleza, el arte y la cultura. En este sentido, en contrapunto de las pedagogías de la esencia, se presenta la posibilidad de pensar una pedagogía del afecto. En tal conocimiento pedagogía es una aventura sin fin, pero no imposible de ser vivido. Es una pedagogía de la realidad, que pretende superar las barreras (mental e institucional), utilizando la positividad como parámetro, la grandeza como modelo. Por último, predicando un estatus científico a afectar, esta pedagogía no aísla el proceso de la vida, pero es la vida misma en sus variaciones de potencia.

PALABRAS CLAVE: Afectividad. Conocimiento. Pasión. Alegría.

$\overline{\text { Artigo recebido em maio de } 2015}$

Aprovado em julho de 2015

Cad. Pes., São Luís, v. 22, n. 2, mai./ago. 2015 


\section{1 | INTRODUÇÃO}

Este artigo persegue elementos conceituais do binômio filosófico Nietzsche-Spinoza1. Ou seja, um conjunto de caracteres comuns que nos permitem aproximar o pensamento de tais filósofos de maneira a criar um istmo, uma extensão ou um alongamento cujas extremidades permanecem como platôs de transmissão de signos. Esses signos, por vezes, ganham corpo, voz e sentido (é quando Nietzsche reconhece as virtudes de seu antecessor); outras, eles surgem de modo racional, quase matemático (é quando Nietzsche chama Spinoza de spine, a aranha do conhecimento). De uma forma ou outra, o que está em jogo é uma perspectiva que afirma a imanência do pensamento, quiçá fortalece a possibilidade de discutir as dimensões de uma nova praxis, distante da tradição hegeliana-marxista. São práticas que não se ausentam dos modos de vida, que mantém a coerência do corpo e do espírito, tão ao gosto da Ética de Spinoza. E é na Ética que a teoria dos afetos (ou da alegria) encontra seu estatuto de cientificidade, sobretudo no livro III: 'A origem e natureza dos afetos'. Essa seção serve como palco central por onde se desdobram as considerações do presente artigo. Portanto, imanência e afetividade são palavras recorrentes no texto, até porque inspiradas pela interpretação de Gilles Deleuze (1925-1995) sobre a obra de Nietzsche e de Spinoza. Desse modo, elas se apresentam como elo de ligação possível entre o conatus e a Vontade de Potência.

Além do mais, a conhecida frase de Nietzsche 'fazer do conhecimento o mais potente dos afetos' é motivo de controvérsias. Por isso, nesse artigo, traçamos um paralelo entre o conceito de afeto em Nietzsche e Spinoza, procurando desmistificar a suposta corrente de harmonia filosófica de suas obras. Da mesma forma, pontuamos as ressonâncias entre o amor dei e o amor fati, contornando, para isso, as noções de Deus e natureza. Depois disso, encontramos uma nota fundamental que se evade da música dionisíaca de Nietzsche e das lentes iluminadas do artesão Spinoza. Ora, essa nota é a alegria. Então, o artigo se debruça nessa direção, identificando duas tonalidades de alegria (a trágica e a intensiva). A partir daí, projetamos uma 'pedagogia do afeto', imbuída da didática do riso e da paixão pelo conhecimento. Em tal pedagogia, os saberes da experiência não são menosprezados, mas compõem um plano comum de expressão da vida e da arte. Assim, assumindo a leitura deleuziana (dos filósofos em destaque) esse artigo pretende revitalizar as chamadas práticas pedagógicas por meio da dinâmica das afecções, inspirado, sobretudo, pelos pressupostos da Ética e da estética nietzschiana. Sendo assim, é possível operar no cotidiano da sala de aula sem tocar-se pela dimensão concreta da afetividade? É o que o presente artigo pretende explorar.

\section{2 | CONHECIMENTO E PAIXÃO}

É verdade que alguns conceitos, palavras ou ideias sugerem relativa aproximação entre Nietzsche e Spinoza. Ora, se Nietzsche confessou em carta a Franz Overbeck, datada de 30 de julho de 1831, sua ligação com o filósofo por meio de teses essenciais da filosofia moderna, não seria blasfêmia colocá-los lado a lado na condição de blocos graníticos do pensamento reacionário.

\footnotetext{
${ }^{1}$ A grande identidade Espinoza-Nietzsche é referida, de maneira específica, por Deleuze (1992, p. 169), em entrevista a Raymond Bellour e François Ewald para o Magazine Litteráire.

${ }^{2}$ Salientamos que o termo 'Pedagogia' não está sendo usado conforme a compreensão deleuziana, manifesta na introdução de 'O que é a filosofia?', ou seja, como uma das idades do conceito, um tipo de pesquisa filosófica que "analisa as condições de criação como fatores de momentos que permanecem singulares" (DELEUZE; GUATTARI, 1992, p. 21). Sua compreensão é tributária do campo das ciências da educação.
} 
Ambos desafiaram sua época, as instituições, a sociedade, a cultura, lançando, assim, para os séculos vindouros enigmas provocadores e pulsantes. O que é reacionário num pensamento é aquilo que não se cansa de pensar, ou seja, de produzir teses, ideias, de contaminar gerações inteiras de estudiosos e comentadores. Não há palavra final que possa servir de porto seguro para aqueles que apreciam a fidelidade da leitura exata, metódica e regrada. Assim é a obra de Nietzsche e Spinoza, pois a cada leitura encontramos um novo ponto de vista, um frescor de ar que sai pela janela e ganha o mundo. Antes de tudo, elas são duas grandes filosofias de vida, cuja dimensão das palavras não se mede apenas pela transposição reflexiva da linguagem, mas pela concretude de seus fundamentos éticos. Se há uma ontologia em Nietzsche é fato que ela é de outra ordem, da ordem do além-do-homem, do ocaso de Zaratustra. Já em Spinoza, ela se torna evidente considerando as preocupações daquela que é considerada sua maior obra: a Ética demonstrada à maneira dos geômetras. Com efeito, a matéria humana e suas possibilidades (potencialidades) é a massa homogênea na qual se detém o filósofo, sobretudo na Ética. Então, o que chamamos de ética poderíamos sem prejuízo professar-lhe a condição de ontologia. No entanto, essa mesma operação se torna um tanto delicada em Nietzsche, pois, ao mesmo tempo em que recusa o poder de um Deus transcendente, ele não define nenhum atributo fixo e estável ao drama do Ser. Pelo contrário, ele desestabiliza toda ordem de valores sobre a terra, desconfia das filosofias da consciência e das religiões que pregam a moral dos fracos e oprimidos. Ou seja, embora exista uma relativa aproximação conceitual entre Nietzsche e Spinoza, ela não elimina as diferenças fundamentais de suas obras. O próprio filósofo alemão, em determinado momento de seu pensamento, refuta Spinoza; aliás, como procede com os demais filósofos. Logo, as tentativas de aproximação devem versar sobre perspectivas muito bem definidas, a fim de que não se deturpe a obra do autor. Nesse caso, a perspectiva da afirmação da imanência e do reconhecimento da afetividade nos parecem cumprir papel fundamental na confecção desse texto.

Com efeito, segundo Deleuze (2002) é possível compreender porque Spinoza foi chamado de materialista. Ao propor o corpo como modelo, o filósofo recusa a perspectiva do pensamento antigo e medieval, uma vez que depõe contra os artifícios da consciência, como também contra a subjugação da moral tradicional pelo pensamento metafísico teísta. Ora, o plano das ideias só tem efeito concreto quando é executado numa dinâmica de ação-reação-afirmação, ou seja, sem a potência do corpo o pensamento não alcança sua forma imanente de criação e efetuação. O que significa uma recusa expressa ao dualismo cartesiano, pois na filosofia de Spinoza a consciência não está num estágio superior ao corpo, tampouco a mente racional é considerada soberana no julgamento das ações. A tese teórica conhecida por paralelismo (DELEUZE, 2002), ilustra esse patamar de igualdade entre mente e corpo e, portanto, coloca o homem como produto da potencialidade de suas ações. Ainda segundo Deleuze (2002, p. 24): "[...] o que é ação na alma é também necessariamente ação no corpo, o que é paixão no corpo é por sua vez necessariamente paixão na alma." No entanto, é o conjunto das experiências positivas, ativas, que enriquecem a dinâmica afetiva da ética spinozista. Por exemplo, sentimos bem estar quando nos alegramos com determinada situação e, com isso, estimulamos a coerência do pensamento. Ao contrário,

\footnotetext{
${ }^{3}$ Importa destacar algumas particularidades da leitura deleuziana em relação ao uso dos filósofos citados (Nietzsche e Spinoza). A interpretação de Deleuze é original na medida em que realiza adaptações, distorções filosóficas intencionais, adaptadas ao seu projeto de tratar a história da filosofia como a 'arte da colagem na pintura', conforme o prólogo de Diferença e repetição: "Parece-nos que a História da Filosofia deve desempenhar um papel bastante análogo ao da colagem numa pintura" (DELEUZE, 1988, p. 19). Por isso, a interpretação deleuziana deve ser tratada com cuidado, diferenciando-se o que, efetivamente, é obra do filósofo em destaque do que é invenção deleuziana.
} 
sentimos desprazer quando algo ameaça nossa estabilidade. O que confere ao papel da ética um eudemonismo essencial, quiçá uma ponta da filosofia antiga presente em Spinoza e, porque não dizer, uma tonalidade socrático-platônica. Embora essa ética manifeste uma recusa expressa ao plano metafísico transcendental, é sabido que, em Spinoza, tanto as ações quanto as paixões circulam numa atmosfera de presente puro, espaço de realização da imanência do pensamento. Portanto, não há uma promessa de final feliz na história, mas a composição de instantes, enriquecidos pela dinâmica dos afetos e pela complexidade das relações.

É claro que se houvesse um profundo conhecimento dessas relações (do corpo com outros corpos, da ideia com outras ideias...) as ações seriam previsíveis e dissociadas da afetividade. Ainda que a lente que vê e julga o mundo é eminentemente individual, ela carece da potencialização dos encontros casuais, da experiência de contato com o outro a fim de estimular as sensações. Isso quer dizer que, na maioria das vezes, temos ideias inadequadas das coisas, jamais temos clareza das causas e das origens daquilo que partilha nosso meio. Então, ainda segundo Deleuze (2002), a consciência desenvolve o artifício de uma tripla ilusão: ilusão da finalidade, ilusão da liberdade e ilusão teológica. Nesse sentido, ele afirma: "A consciência é apenas um sonho de olhos abertos" (DELEUZE, 2002, p. 26). Isso significa que nem tudo está sob controle, que as motivações e os apetites exercem influência direta nas decisões que tomamos. Significa, inclusive, que a consciência não é a única produtora do pensamento e, desse modo, não tem poder absoluto sobre sua origem. Ela é apenas um mecanismo de transição entre o desejo (cujo termo spinozista mais apropriado é a expressão conatus) e os estados de afecções que determinam a ação. Assim, é fácil imaginar que tanto Spinoza quanto Nietzsche foram precursores da noção de inconsciente na psicanálise. Essa afirmação é perfeitamente verificável na Genealogia da moral, quando o filósofo alemão denuncia os mecanismos que constituíram a mentalidade gregária da civilização. Em Spinoza, percebemos uma gradativa desvalorização da consciência em relação aos processos de constituição do pensamento. Logo, podemos aproximar ambas as filosofias de um movimento antiteleológico que desconfia das verdades universais e da doutrina das causas finais.

Agora, referindo-se a carta de Nietzsche citada anteriormente, a frase que define sua aproximação com Spinoza: 'fazer do conhecimento o mais potente dos afetos' merece destaque no conjunto dessa abordagem. Sabemos que tanto Nietzsche quanto Spinoza opera uma naturalização dos afetos na medida em que desvalorizam a moral tradicional alicerçada em valores metafísicos. Não seria absurdo dizer que o amor dei e o amor fati comungam de relações muito próximas, quando se trata da condição humana. Isso não significa que tenham a mesma direção de possibilidade e sentido, tampouco os mesmos alvos de crítica. No entanto, existe uma virtude afirmativa nessa tipologia do amor. Quer seja com a expressão máxima da alegria spinozista, quer seja com o sofrimento trágico nietzschiano, o fato é que ambos apontam para o novo homem, distante das imagens idealistas ou religiosas. Em tal personagem, o projeto ético encarna as forças do destino, ou seja, uma espécie de política dos afetos cuja dinâmica essencial corrobora com a vontade de potência (ou conatus) na condução dos instintos liberadores. Essa afirmação é pactuada com a seguinte passagem da Ética (Livro 3, escólio da proposição IX):

Além disso, entre apetite e desejo não há nenhuma diferença, excetuando-se que, comumente, refere-se o desejo aos homens à medida que estão conscientes de seu apetite. Pode-se fornecer, assim, a seguinte definição: o desejo é o apetite juntamente com a consciência que dele se tem. (SPINOZA, 2011, p.106).

Ora, se o desejo é 'o apetite juntamente com a consciência que dele se tem' é porque o esforço da individualidade se sobrepõe ao caráter transcendente da natureza humana. Nessa condição, não existe possibilidade da ética spinozista partilhar dos elementos de uma ética normativa, por 
exemplo, pois não há predomínio do interesse coletivo em guiar o ser humano nas decisões políticas, apenas a procura particular de cada corpo em satisfazer sua vontade. Não é aleatório que um corpo é medido pela capacidade de expandir-se por meio de paixões alegres, em perseverar na positividade do autoconhecimento e da autodeterminação. Portanto, 'fazer do conhecimento o mais potente dos afetos' remete a condição de tornar o conhecimento um afeto para poder ser motivo de afecção. Dessa forma, ele conduz nosso agir na medida em que sua atividade exige esforço, duração e profundidade. Quanto mais se afasta das paixões comuns, mais ele (o conhecimento) fortalece o grau de liberdade no indivíduo. E é essa a trajetória do amor dei: uma forma de compreensão expansiva que se funde com o universo das coisas naturais, que enxerga a harmonia de Deus na dimensão infinita de seu amor.

Talvez fosse necessário definirmos a noção de Deus em Spinoza afim de que não se confunda tal noção com o conceito das religiões monoteístas, tampouco com a ideia de amor divino. Com efeito, na Ética (Primeira Parte, Deus, definição 6), encontramos a seguinte sentença: "Por Deus compreendo um ente absolutamente infinito, isto é, uma substância que consiste de infinitos atributos, cada um dos quais exprime uma essência eterna e infinita" (SPINOZA, 2011, p.13). Isto quer dizer que não se trata de um Deus antropomorfizado por sentimentos humanos, mas de uma figura absoluta em si mesma e que não carece de determinação. Em tal figura, o caráter imanente é uma condição na medida em que ela não está separada do mundo, uma vez que o mundo e a figura de Deus são a mesma coisa. Essa circunstância põe por terra a mitologia da criação do mundo por uma entidade divina, já que o mundo é uma produção necessária da potência infinita e intrínseca de Deus. É nessa direção que se apresenta, segundo Deleuze (2002), a grande tese teórica do spinosismo, qual seja: a de 'Deus sive Natura'. Tal tese refuta tanto a herança cartesiana quanto a tradição teológica medieval, pois a ideia de Deus se funde com o conceito de natureza, isto é, como uma única e mesma substância existente. Desse modo, não existem relações de dominação entre uma esfera e outra, já que o panteísmo (o ateísmo potencial de Spinoza) é desprovido de humanidades. Portanto, Deus não é um ser ético, porque não está submetido aos padrões humanos e, em razão disso, absolutamente livre. Entretanto, o homem submetido ao mores geométrico de Spinoza busca no plano horizontal da ética, o que Ihe corresponde no plano vertical da metafísica (entendida como ideal). Ou melhor: ele procura assemelhar-se em conformidade com a sua natureza, busca adquirir perfeição no seu 'agir' para se harmonizar com o seu 'ser'.

Entretanto, quando Nietzsche fala em 'afeto' como motivação do conhecimento devemos ficar atentos ao sentido empregado pelo filósofo. Ora, ele fala pela boca de Spinoza, uma vez que raramente utiliza o conceito de 'afeto' para referir-se ao mecanismo da Vontade de Potência, por exemplo. Sabemos, inclusive, que a frase citada acima não é influenciada diretamente pelo filósofo judeu, mas pela leitura que Nietzsche realiza da obra de outro estudioso da filosofia. Com efeito, tal obra chama-se História da filosofia moderna e seu autor (professor da Universidade de Heidelberg) é Kuno Fischer (1824-1907). É pelo olhar deste historiador que Nietzsche formula a conhecida frase cujo efeito semântico deve ser restritivo ao contexto e ao estilo filosófico utilizado (nesse caso, as cartas do filósofo alemão). Para Nietzsche, o conhecimento está muito mais próximo de uma paixão do que um afeto. Na Gaia Ciência, o aforismo 123 reforça esse ponto de vista:

O conhecimento sendo mais que um meio.- Mesmo sem esta nova paixão — refiro-me à paixão do conhecimento - a ciência seria fomentada: até agora a ciência cresceu e se desenvolveu sem ela. A boa fé na ciência, o preconceito a seu favor, que hoje predomina em nossos Estados (até na Igreja, antes), no fundo baseia-se no fato de que esse incondicional ímpeto e pendor manifestou-se raramente nela, e de que justamente a ciência não é considerada uma paixão, mas um estado e um ethos. (...) (NIETZSCHE, 2001, p. 146).

Cad. Pes., São Luís, v. 22, n. 2, mai./ago. 2015 
Se o conhecimento quer ser mais que um 'meio', como refere o título do aforismo 123, é porque a visão de uma ciência superficial em seus objetivos não interessa ao filósofo. Por isso, a condição da paixão remete ao esforço máximo da Vontade de Potência em afirmar-se na tensão trágica da vida. Contra a imagem desta ciência estéril, fria, ambiciosa, ele oferece a imagem de uma Gaia Ciência, procurando conciliar elementos da ordem racional com a paixão pessoal pelo conhecimento, ou seja, nada mais que o esforço de aproximação entre o intelecto e a Vontade. Nesse sentido, podemos associar essa afirmação à noção de amor fati (amor ao destino), uma vez que o empreendimento pessoal pela superação de barreiras psíquicas exige a desconstrução dos valores cristalizados pela sociedade (Ciência, Estado, Igreja). Essa fórmula caracteriza a condição do ethos nietzschiano no sentido de reverenciar a grandeza do homem, ou seja, daquele que é indiferente ao sofrimento, que afirma seu valor sob qualquer adversidade. Portanto, há de se imaginar que esse 'afeto' em Nietzsche é de outro gênero. Ele é o contrário de um afeto passivo, pois está sempre em permanente atividade. É mais intenso que outros afetos (agregando força e potência). Consequentemente, ele só pode ser uma paixão alegre que se confunde com a experiência da aprendizagem humana.

Porém, nem tudo são flores ou está em perfeita harmonia. A paixão também é um elemento de desassossego, por vezes egoísta e irracional ao extremo. Trata-se de transformar o conhecimento em paixão e, por isso, Nietzsche recorre ao pensamento antigo, precisamente aquele divergente da matriz socrático-platônica. Assim, encontra no estoicismo a firmeza de caráter necessária para afirmar a doutrina do além-do-homem (o homem virtuoso), ou seja, aquele que encontra a felicidade dentro de si e é imune aos ataques exteriores. Claro: não é possível afirmar que a noção de além-do-homem seja exatamente igual ao homem virtuoso do estoicismo, uma vez que a primeira decorre da consequência do niilismo na História, da transvalorização de todos os valores. Outra influência é a paixão dionisíaca que se assenta no fundamento trágico da vida, sem a desmedida e a embriaguez de Dionísio dificilmente o filósofo valorizaria o saber instintivo sobre a realidade. Ora, importa saber que o conhecimento deixa de se tornar um meio para se tornar uma paixão, como afirma Sévérac (2009, p. 50), "A paixão é, com efeito, o domínio de um impulso, de um afeto sobre todos os outros: o homem apaixonado tem apenas um único objetivo, satisfazer este impulso." Significa que essa paixão tornou-se obstinação e, por isso, ela não pode ser refutada ou dominada por outro afeto. Ela não pode renunciar ao objeto-paixão, como a fidelidade estoica, mas perseguir seu objetivo de maneira intensa e substancial. É fato que tal condição provoca, inclusive, alteração no comportamento, uma vez que o indivíduo se torna cada vez mais compenetrado em seus objetivos. Para o apaixonado não importa o que os outros pensam sobre a forma de conduzir sua paixão, pois está ciente de si mesmo e, frequentemente, opõe-se ao conceito geral da maioria da população. Ou seja, a partir da própria interpretação do conhecimento, ele busca um apanágio de verdade e, assim, sustenta uma espécie de orgulho por trilhar caminhos desconhecidos do homem comum (veja-se a epopeia de Zaratustra). É nesse sentido, que o conhecimento se transforma em paixão, que a vida ganha uma meta e uma direção, de maneira que tudo que crie empecilho para o desenvolvimento contínuo dessa virtude deva ser deixado em segundo plano. Portanto, a arte de se apaixonar é muito mais valiosa que o objeto da paixão.

Esse ponto de vista pode ser reforçado ainda pelo livro V, aforismo 429 da Aurora. Nele, Nietzsche associa cultura e barbárie, cristianismo e moral. Lembramos que tanto Aurora quanto Gaia Ciência são obras consideradas da segunda fase do pensamento nietzschiano, embora esta última, seja descrita como produto de um período de transição do filósofo (GIACOIA JUNIOR, 2000). A segunda fase é caracterizada por uma espécie de positivismo científico, ou seja, Nietzsche procura elevar o valor do conhecimento científico, afastando-se da metafísica de artista 
A PEDAGOGIA DO AFETO | Deniz Alcione Nicolay

(momento que corresponde à primeira fase da obra). $\mathrm{O}$ aforismo citado diz o seguinte:

A nova paixão.- Por que tememos e odiamos nós um possível retorno à barbárie? Porque ela faria os homens mais infelizes do que são? Ai, não! Os bárbaros de todos os tempos tinham mais felicidade: não nos iludamos! — O fato é que nosso impulso ao conhecimento é forte demais para que ainda sejamos capazes de estimar a felicidade sem conhecimento ou a felicidade de uma ilusão forte, firme; é penoso simplesmente representarmo-nos tais estados!(...) O conhecimento, em nós, se transmudou em paixão, que não se intimida diante de nenhum sacrifício e, no fundo, nada teme, a não ser sua própria extinção; (...) (NIETZSCHE, 2014, p. 194).

Nessa passagem, observamos que o 'impulso ao conhecimento' é um ato de coragem. Por um lado, ele não carrega a marca da atividade gregária, tampouco o peso dos valores morais, o que significa que partilha de uma natureza de caráter nobre, em certo sentido: aristocrático. Entretanto, isso não significa poder (sobretudo riquezas), mas, ao contrário, ele exige uma condição de vida simples, um gesto de heroísmo contra as adversidades do mundo (tal como a vida de Nietzsche e Spinoza). Por outro lado, a obra do conhecimento é o esforço de humanização da natureza, o que coloca a consciência como uma atividade tardia no ser humano. Na dinâmica das forças todos os outros impulsos foram reduzidos ao segundo plano, porque um único impulso prevaleceu: a paixão pelo conhecimento. Com efeito, a vida não teria sentido se o esforço da interpretação não nos levasse a criação do novo, a descoberta de outros caminhos pelas veredas da civilização.

\section{3 | AFETO, ALEGRIA E EXPERIÊNCIA}

Embora consideremos as diferenças conceituais entre Nietzsche e Spinoza, inclusive a distância temporal que separa os dois filósofos, é possível definir uma nota de convergência entre suas filosofias. Ora, essa nota de convergência carrega uma espécie de amálgama entre o conatus spinozista e a Vontade de Potência nietzschiana. Talvez a maior contribuição para pensarmos uma 'pedagogia do afeto' seja a abertura que se expressa na obra de ambos, uma vez que valorizam os saberes da experiência e, ao mesmo tempo, partilham da singularidade do acontecimento. Antes disso, é preciso diferenciar a natureza das afecções, ou melhor, da terminologia utilizada por Spinoza, já que Nietzsche prefere a palavra 'impulso' ou 'paixão' ao termo 'afeto'. Nesse sentido, Deleuze (2009), nos cursos de Vincennes (1978-1981), alerta para a distinção de dois termos utilizados por Spinoza, sobretudo na Ética. Esses termos são as expressões affectio e affectus cujo significado não ilustra a mesma palavra, uma vez que, afeto se refere ao affectus e afecção ao termo affectio. Ora, toda a Ética foi escrita em latim e sabemos da dificuldade de alguns tradutores em interpretar expressões da linguagem clássica humanista. Ao diferenciar esses termos, Deleuze (2009) quer afastar o pensamento de Spinoza das demais correntes filosóficas do período, ou seja, daquele período que abrange os séculos XVI e XVII, portanto, meados da modernidade. Como também é muito provável que o professor de Vincennes encontre no filósofo judeu uma concepção de conhecimento que destoe do empirismo e do racionalismo; é claro: concepção esta alicerçada na construção de um plano de imanência. Nesse sentido, podemos partilhar da seguinte definição: "O affectus é então a variação contínua da força de existir de alguém, enquanto esta variação é determinada pelas ideias que ele tem" (DELEUZE, 2009, p. 29). Ora, sabemos que a 'força de existir de alguém' se expressa por meio de paixões, tanto paixões alegres quanto paixões tristes. A primeira é toda paixão que aumenta nossa potência de agir e, a segunda, é aquela que, de alguma maneira, diminui nossa potência de agir. É exatamente a definição dada por Spinoza na Ética, na terceira parte (A origem e natureza dos afetos), definição 
III e, na sequência, o primeiro postulado. Observamos o que afirma esse postulado: "O corpo humano pode ser afetado de muitas maneiras, pelas quais sua potência de agir é aumentada ou diminuída, enquanto outras tantas não tornam sua potência de agir nem maior nem menor" (SPINOZA, 2011, p. 99). É quase a mesma afirmação de Deleuze. Além de diferenciar ideia de afeto, ele aponta que no entendimento da variação contínua não se trata da comparação entre uma paixão e outra, mas de queda de intensidade da potência de agir. Tal movimento justificaria o poder do déspota e do sacerdote, por exemplo, uma vez que ambos utilizam as paixões tristes a fim de diminuir o estado de força de seus súditos. Eles têm necessidade da tristeza como artifício moral para expandir seus domínios, assim como, a pequena política de nosso tempo tem necessidade da tristeza docente para perpetuar o poder. Por esse caminho, podemos nos aproximar de Nietzsche. Com efeito, se pensarmos a partir da Genealogia da moral e suas teses sobre 'ressentimento, má consciência e ideal ascético', o caminho da história e da religião em direção ao sentido niilista da vida, percebemos que o sacerdote ascético não está tão longe do sacerdote de Spinoza, ou melhor, da interpretação que Deleuze faz de Spinoza. No entanto, para o autor da Ética a moral judaico-cristã não é um problema de primeira ordem no que concerne a variação de intensidade do conatus, já que esta é colocada no âmbito das relações entre os corpos. É como se a constituição da subjetividade se desse por meio da dinâmica afetiva, estabelecida no encontro com o outro, e não tributária apenas da má consciência das religiões monoteístas. Nesse sentido, para não sermos dominados por afetos passivos é necessário estabelecer (e incorporar) relações de força com outros componentes da natureza, fortalecendo nosso próprio corpo. O que sugere a alegria como 'o mais potente dos afetos', pois é a sua constância que determina a atividade dos afetos, enquanto seu inverso (a tristeza) se prende na passividade. Portanto, aqui está o 'elo de convergência' das filosofias de Nietzsche e Spinoza: a alegria.

No entanto, torna-se vital nesse momento definirmos a noção de afecção ou affectio, mesmo que ela pareça pressuposta nas passagens anteriores. Ora, se colocamos a alegria como motivação máxima da potência de agir é porque existe uma relação inicial que define a natureza da afecção. A alegria está sempre numa dinâmica crescente, muitas vezes desproporcional a sua própria causa; mas, nem por isso deixa de influenciar diretamente modos de vida. Ela é definida pelo seu poder de contágio, de afecção, pois exige do corpo afetado uma descarga instantânea de emoções. Não se pode estar alegre pela metade, quanto menos fingir que estamos embriagados de afetos. A alegria flerta de maneira incondicional com o real, uma vez que é quase impossível que se possa ficar contente sem nenhuma motivação aparente; porém, ficamos alegres pela conquista de um desejo, de algum objeto de satisfação, mesmo que há muito tempo visado. Entretanto, isso não é uma regra. Por vezes, a alegria surge de condições adversas, sem nenhuma motivação explícita, apenas por partilhar da harmonia cósmica e da simplicidade da vida cotidiana. Porém, mesmo nessa condição, ela exige um esforço de afirmação, quer seja pela ação voluntária do indivíduo, quer seja pela relação comunicativa estabelecida com o outro. E, é nessa direção que destacamos o conceito de afecção: "A affectio é uma mistura de dois corpos, um corpo que é dito agir sobre o outro, e o outro que vai escolher a marca do primeiro. Toda mistura de corpos será chamada afecção" (DELEUZE, 2009, p. 30). Ora, se a 'mistura de corpos' é chamada de afecção é porque a ontologia spinozista não vê diferença de espécie entre um afeto e outro, mas diferença de graus e intensidade. Com efeito, se existe apenas uma única substância (substantia) em toda a realidade e as demais são atributos ou determinações desta substância é possível inferir que o corpo afetado está predisposto ao movimento afetivo do corpo afetante. Numa dinâmica de produção e autoprodução, as máquinas desejantes (para utilizar um conceito de Deleuze e Guattari no Anti-Édipo) realizam operações de acoplamento e absorção. É por isso que Deleuze identifica uma identidade Nietzsche-Spinoza em toda sua produção filosófica, sobre- 
sobretudo na interpretação de uma teoria dos afetos. Ele não vê ambas as filosofias como universo aparte, mas a projeção comum de certo modo de vida cujos valores se estabelecem numa pragmática do instante. Nesse sentido, ele aproxima o conceito de 'afeto' entre os filósofos (Nietzsche-Spinoza) no sentido de validar essa identidade comum, conforme verificamos nessa passagem: "O que Nietzsche chama "afeto" é exatamente a mesma coisa que Spinoza chama afeto, é neste ponto que Nietzsche é spinozista, a saber, são as diminuições ou os aumentos de potência..." (DELEUZE, 2009, p. 165). No entanto, temos a impressão de que Deleuze (2009) procura 'forçar' essa identidade, uma vez que já verificamos as diferenças conceituais entre os filósofos. Claro, é possível um 'Nietzsche spinozista', mas dificilmente um Spinoza nietzschiano. Por isso, podemos afirmar que a alegria é esse elo na teoria dos afetos, já que lança a existência no caminho da perfeição humana. Não a promessa de bem aventurança do espírito, nem a virtualidade do plano das ideias, mas tão somente a alegria de viver em liberdade. E é nessa condição que nos aproximamos da potência de Deus, da partilha do sensível e da experiência de aprender o real.

Isso significa que mesmo considerando a alegria como elo essencial na obra dos filósofos é possível verificar uma situação de instabilidade em relação à tonalidade afetiva, já que esta acompanha a variação de potência e a intensidade dos afetos. Talvez tenhamos tonalidades diferentes de alegria tratando-se de Nietzsche e Spinoza. Nesse sentido, é possível reconhecermos uma forma de alegria trágica no primeiro e uma forma de alegria intensiva no segundo. Entretanto, é justo que o leitor atento discorde de tal proposição, pois alegria é alegria e nada mais. Além disso, são poucos os comentadores que se debruçam sobre essa questão. Acontece que as evidências em tais obras nos impulsionam nessa direção, sobretudo na teoria dos afetos. Não é de praxe julgar a obra do autor pela sua condição de vida, mas tratando-se de Nietzsche e Spinoza poderíamos afirmar, sem grande margem de erro, que o estilo pessoal de ambos proporcionou a vitalidade conceitual de suas obras. Por exemplo, a vida frágil do corpo de Spinoza contrasta com um dos maiores sistemas filosóficos de todos os tempos, a precisão do polidor de lentes busca a perfeição da visão, por isso, a pergunta de Deleuze (2002, p. 18): "Como explicar que essa vida frugal e sem haveres, consumido pela doença, esse corpo delgado, frágil, esse rosto oval e moreno com olhos negros e brilhantes deem a impressão de serem percorridos pela própria Vida, de ter um poder idêntico à vida?" Essa argumentação de Deleuze nos leva a acreditar numa forma de alegria intensiva, que procede por acúmulo de potência (capacidade de síntese) e velocidade de devires (proposições axiomáticas). Ela é o pano de fundo da teoria dos afetos porque partilha dos instantes vividos e só se torna o seu reverso (a tristeza) a custo da diminuição da potência de agir. O conatus é exatamente o esforço que desprende a alegria de seu estado de submissão, ampliando a própria potencia de agir. Nesse sentido, destacamos a seguinte passagem: "É inevitável aceitar, sobre esse ponto, o que diz Espinoza na Ética: a única afeição é a alegria (e seu contrário, a tristeza); qualquer outra afeição não é mais que uma modificação dessa afeição primeira, porquanto está esta submetida às eventualidades do acaso e da sorte" (ROSSET, 2000, p. 12). Se a única 'afeição' é a alegria é porque independe da condição de motivação subjetiva do sujeito, ou seja, ela não é exclusividade de um único ponto de vista, mas coopera, ao mesmo tempo, com a natureza do corpo exterior. O oposto (a tristeza) está na mesma condição. Aqui se desenha a performance de outro conceito utilizado na Ética por Spinoza: occursus (encontro). Ora, é a dinâmica de encontros entre os corpos que determina relações de composição (ou decomposição) dos estados de ânimo (Deleuze (2009) prefere utilizar a palavra potência). Portanto, esta modalidade de alegria (intensiva) está sempre em evolução, pois ela "não é diretamente má", conforme a quarta parte: A servidão humana ou a força dos afetos, proposição XLI da Ética (SPINOZA, 2011, p. 184), ou seja, motivada pelas paixões alegres, ela é o único caminho para a beatitude da ação e, consequentemente, para a formação ética. 
Em Nietzsche essa forma de alegria toma outros contornos. Com efeito, ela está próxima da expansão de potência via estados de elevação da sensibilidade individual. Porém, mesmo os momentos de declínio em Nietzsche são produtivos. Se considerarmos os estados valetudinários do filósofo veremos que a um instante de dor e sofrimento ocorre, em sequência, relâmpagos de uma lucidez ímpar. Tal afirmação pode ser analisada na obra de Pierre Klossowski (Nietzsche e o Círculo Vicioso) ${ }^{4}$ cujas teses recaem a partir da leitura das cartas de Nietzsche. De alguma forma, tentando descrever o 'inconsciente' do filósofo, esse autor persegue a trajetória criativa da obra até deparar-se com as fronteiras da loucura (a anulação da consciência). Ou seja, esse ponto de vista reforça a ideia de que a alegria em Nietzsche é sempre paradoxal, uma vez que esta é tributária do sentimento trágico da vida. Também não seria exagero afirmar que a alegria em Nietzsche é produto da antiga estética grega, cujas figuras de Apolo e Dionísio demarcam a condição potencial de expressão do belo. Além disso, ao interpretar o período arcaico da cultura grega, o filósofo cria sua versão para o fundamento trágico da arte. Desse modo, inspirado no modelo heleno que celebra a vida, mas sem negar o esfacelamento e a destruição, ele enxerga um mundo determinado pela Vontade de Potência. Vontade que é (ela própria) uma competição paradoxal entre as forças ativas e reativas: "A Vontade de potência é uma competição que se desenrola no campo da livre construção das formas. Mas toda forma é a exteriorização de uma força" (GRANIER, 2009, p. 97). Isso significa que a força que se impõe é produto da afirmação do homem superior, determinado na condição de um 'querer criador' e esse, por sua vez, na transfiguração da matéria bruta em obra de arte. Ora, o êxtase da Vontade provoca o extravasamento da alegria, muitas vezes contido por pressões exteriores e pela determinação das forças reativas. E é na transformação dessa modalidade de forças que o filósofo, imbuído de requintada sensibilidade musical, procura aproximar arte e vida. É evidente que o elo dessa aproximação é a alegria trágica, contraditória e fundamental em Nietzsche. Nessa direção apresentamos a seguinte afirmação de Clement Rosset (2000, p. 25): "Por isso, direi em uma palavra, que só há verdadeira alegria se ela é ao mesmo tempo contrariada e se está em contradição com ela mesma: a alegria é paradoxal ou não é alegria." Essa margem do ilógico e do irracional determina a face dionisíaca da arte criadora em Nietzsche. Logo, o homo dionysiacus é aquele que surge embriagado de alegria, um desatinado que supera o homem comum. Ao superar o modo de vida moral do homem comum, ele demonstra toda face cruel e egoísta dessa modalidade de alegria, uma vez que não mede esforços para atingir a própria satisfação. Por outro lado, essa forma de 'loucura real', que é a alegria trágica, procura evitar a doença psicológica e os artifícios da ilusão. Portanto, ela afirma uma condição vital para o aumento de potência sem a qual a vida em geral não tomaria consciência das dimensões e possibilidades do instante vivido.

No entanto, não estamos falando de duas coisas absolutamente diferentes: a alegria em Nietzsche e Spinoza, intensiva e trágica. Estamos falando de uma tonalidade diferente porque as fontes de onde provém não são da mesma origem (a natureza e o indivíduo). Em Spinoza, ela assume a condição de signo universal, paralelo ao principio de 'Deus sive Natura' e apresenta-se como a chave mestra na leitura da Ética, pois sua compreensão na teoria dos afetos determina o papel do desejo e da dinâmica relacional afetiva. Já em Nietzsche, a alegria está presa na interpretação trágica da vida que, aliada ao conceito de Vontade de Potência, manifesta um duelo perene na superação de si mesmo. Agora, tanto uma quanto outra são armas contra a ilusão e o ressentimento, ambas instauram a concretude da consciência, negam a finalidade e o utilitarismo

\footnotetext{
${ }^{4}$ Gilles Deleuze (1998, p. 289) na Lógica do Sentido escreve um de seus apêndices sobre o referido autor Klossowski ou os corpos-linguagem.
} 
dos valores. Por isso, elas estão projetadas no plano de imanência como supra realidade, ou seja, distantes de qualquer julgamento moral, elas afirmam a positividade de tudo que se efetiva, quer seja no homem, quer seja na natureza.

\section{4 | A PEDAGOGIA DO AFETO}

Após as distinções das linhas anteriores, é possível afirmar que tal modalidade de pedagogia está totalmente afastada das pedagogias da consciência, daquelas que colocam o indivíduo como produto exclusivo da razão histórica. Tampouco se aproxima das pedagogias da reprodutibilidade social, isto é, das práticas que alocam trabalhadores para o emergente mercado capitalista. Ela se constitui numa terceira via do conhecimento humano e, quiçá, numa prática sem modelos pré-definidos. Não significa uma atmosfera de 'pode tudo', de sentimentalismo vazio ou de euforia pela mudança radical. Na dinâmica das afecções a que, de uma forma ou outra, estamos sempre condicionados, ela surge como possibilidade de aumentar nossa potência de agir, daí estarmos predispostos a experimentar modos de saber nada convencionais, pois partem da realidade e da natureza dos acontecimentos. Por isso, a alegria é o fator determinante para o aumento dessa potência de agir e sem ela a pedagogia retorna ao ranço moral do discurso pessimista. Assim, é justo partilhar da seguinte colocação: "Perante essa postura escatológica e teleológica eleva-se o riso corretivo e saudável que leva a ultrapassar toda rejeição da vida, atingindo a alegria, a leveza" (BARRENECHEA, 2014, p. 133). O que significa a possibilidade de pensar a inocência dos saberes, distante da metafísica e do juízo das religiões monoteístas, uma vez que a verdade é apenas questão de interpretação. Assim como, o louco dionisíaco que esquece a memória individual para viver o instante coletivo, também a pedagogia do afeto esquece os clichês e os roteiros redundantes das práticas pedagógicas para reaprender as fontes. Portanto, as filosofias de Nietzsche e Spinoza são o pano de fundo no qual se sustenta essa pedagogia. Ela não reinventa a roda, mas prefere fazê-la dançar no 'sabá dos sabás'.

Por isso, alegra-nos a possibilidade de pensar tais dimensões na pedagogia e, de maneira ampla, na educação, já que na maioria das vezes assistimos ao desafio diário de cada professor em levar para a sala de aula um pouco da esperança que anima a vida. Às vezes, nem ele próprio tem esperanças, sobrecarregado pelo fardo da rotina e pelo burocratismo ineficiente que engessa a criatividade e o prazer. A via da pedagogia do afeto quer contribuir para a saúde do corpo do docente, seu bem-estar em fazer o que gosta, em animar a magia do ensinar e do aprender. Parte-se de um estado de liberação dos afetos reprimidos para o círculo poiético de tessitura das práticas pedagógicas, ou seja, a partilha de um espaço que harmonize mente e corpo, alegria e vontade, ética e estética, tal como deveria ser o espaço da sala de aula inspirado pela afetividade. Entretanto, tais colocações não devem confundir-se com metodologias de autoajuda, tampouco com a retórica vazia de soluções milagrosas. O que está em jogo é o esforço de um modo de ser e pensar, que recusa os moralismos de toda ordem, que discute os fundamentos do pensamento representacional (marca incondicional da pedagogia moderna). 


\section{5 | CONSIDERAÇÕES FINAIS}

A teoria dos afetos de Spinoza (expressa na Ética) é perfeitamente assimilável aos pressupostos filosóficos de uma ontologia radical. Ninguém antes de Spinoza colocou o indivíduo em tal posição, ou seja, na condição de sentir e experimentar a concretude das ideias. A clássica interrogação spinozista 'O que pode um corpo?' pode ser aprimorada pelo viés nietzschiano e se manifestar da seguinte forma: 'Do que você é capaz?'Ora, distante do cartesianismo, do humanismo e, de certa forma, do existencialismo, esse amálgama Nietzsche-Spinoza provoca a aurora de uma nova ética; uma ética que não exprime distinções entre corpo e espírito, que se fundamenta nas paixões alegres a fim de aumentar a potência de agir. Por isso, todo esforço realizado nessa direção merece atenção dos atores envolvidos e dos sistemas que validam tais práticas. A educação em Spinoza e em Nietzsche é voltada para a realidade do tempo presente, uma vez que exige a superação das barreiras psíquicas (criadas pelo indivíduo ou pelas instituições). Essa motivação essencial, sem a qual o projeto de vida reacionário não se realiza, recebe terminologias diferentes na obra dos filósofos: conatus ou Vontade de Potência. Se, por um lado, não significam a mesma coisa; por outro, esses dois conceitos são fundamentais em qualquer tentativa de aproximação que alie o amor dei e o amor fati numa política dos afetos. Por isso, em Spinoza quanto mais nos guiamos pelo exercício do conhecimento mais nos aproximamos de Deus, ou seja, o amor pelo conhecimento é parte indissociável do pleno amor de Deus. Em Nietzsche, o conhecimento é motivado pelo pathos trágico, por uma vontade obstinada de transformar o sofrimento em arte. No entanto, essa forma de arte justifica a vida, transforma a paixão pelo conhecimento na grande aventura do espírito humano. Então, é possível definir paralelos entre os pontos descritos nesse texto, entre Nietzsche, Spinoza e a pedagogia do afeto: $1^{\circ}$ Tanto um como outro valorizam a pulsação instintiva do indivíduo, estimulando a naturalização dos afetos. $2^{\circ}$ Ambos rejeitam o domínio da consciência como única ferramenta de manifestação do pensamento humano. $3^{\circ}$ Ambos procuram dar um estatuto de cientificidade aos sentimentos e motivações da vida. E, por fim, 4: A alegria em Nietzsche e Spinoza é 'o mais potente dos afetos', mesmo com variações de força e intensidade, ela se constitui na mola propulsora da concepção ética, dos modos de vida e das relações afetivas.

Portanto, a pedagogia do afeto não é matéria de ficção. Ao partir da alegria trágica de Nietzsche e da alegria intensiva de Spinoza, ela persegue a legitimidade do conhecimento, de tudo que se aprende. Porque ensina que aprender é um fenômeno de corpo todo, da vontade perene de superar-se no tempo e no espaço. Aprender é da ordem do infinito, do desejo insaciável pelas metáforas da realidade. Ou seja, aprender na pedagogia do afeto deve aproximar-se da vida, potencializar os encontros positivos e a dinâmica das relações humanas na escola. Em certo sentido, ela invoca pressupostos éticos e estéticos em relação à perspectiva de formação permanente, pois não acata a dualidade explícita das matérias de ensino (como se um único caminho determinasse a vitalidade do conhecimento). $O$ docente formador só se forma ao formar, na medida em que expande essa condição da alegria, em que se aceita como corpo inacabado na arte de engendrar a paixão. 
A PEDAGOGIA DO AFETO | Deniz Alcione Nicolay

\section{Referências}

BARRENECHEA, M. A. Nietzsche e a alegria do trágico. Rio de Janeiro: 7 Letras, 2014.

DELEUZE, G. Conversações. Rio de Janeiro: Ed. 34, 1992.

Cursos sobre Spinoza (Vincennes, 19781981). Fortaleza: Eduece, 2009.

. Diferença e repetição. Rio de Janeiro: Graal, $\overline{1988 .}$

Espinosa: filosofia prática. São Paulo: Escuta, 2002.

Lógica do sentido. São Paulo: Perspectiva, 1998.

DELEUZE, G.; GUATTARI, F. O que é a filosofia? Rio de Janeiro: Ed. 34, 1992.

GIACOIA JUNIOR, O. Nietzsche. São Paulo: Publifolha, 2000.

GRANIER, J. Nietzsche. Porto Alegre: L \& PM, 2009.
KLOSSOWSKI, P. Nietzsche e o círculo vicioso. Rio de Janeiro: Pazulin, 2000.

NIETZSCHE, F. Genealogia da moral. São Paulo: Companhia das Letras, 1998. Letras, 2001.

A gaia ciência. São Paulo: Companhia das

. Obras incompletas. São Paulo: Ed. 34, 2014. (Coleção fábula).

ROSSET, C. Alegria: a força maior. Rio de Janeiro: Relume Dumará, 2000.

SÉVÉRAC, P. Conhecimento e afetividade em Spinoza. In: MARTINS, A. (Org.). O mais potente dos afetos: Spinoza \& Nietzsche. São Paulo: Martins Fontes, 2009. p. 17-31.

SPINOZA, B. de. Ética/Spinoza. Tradução Tomaz Tadeu. Belo Horizonte: Autêntica Editora, 2011. 